\title{
LETTERS
}

\section{Addressing challenges with current therapies for obstructive sleep apnea}

We read with interest the responses to our recent review of the diagnosis and treatment of obstructive sleep apnea (OSA). ${ }^{1}$ We agree that challenges with current therapies for OSA necessitate the study of newer and personalized treatments to improve clinical outcomes, treatment adherence and patient satisfaction. As indicated by Dr. Pupko, ${ }^{2}$ the use of dronabinol in the treatment of OSA is one of several such approaches to improve OSA severity and sleepiness. ${ }^{3}$ The PACE (Pharmacotherapy of Apnea by Cannabimimetic Enhancement) study showed early but promising results of cannabimimetic therapy, which should be validated through comparisons to established OSA treatments over a longer follow-up period with larger patient cohorts.

Highlighting the difficulties that some patients with OSA experience tolerating continuous positive airway pressure (CPAP) therapy, Drs. Rotenberg and Pang stress the importance of surgical treatments to improve patient outcomes. ${ }^{4}$ We did not find a strong body of high-quality literature to justify the use of upper airway surgery as a first-line treatment for OSA. Specifically, there are limited data on disease recurrence, and the existing literature suggests that complications are not infrequent. Our conclusions are supported by a recent large meta-analysis by the Canadian Agency for Drugs and Tech- nologies in Health, which also found insufficient evidence to support upper airway surgery as first-line therapy for OSA except in highly selected patients for whom other therapies (CPAP or oral appliances) are intolerable or unacceptable. ${ }^{5}$ We look forward to higher-quality studies, including robust comparisons to currently accepted treatments for OSA, that will help to clarify the role of surgery in the management of OSA. In the meantime, although intolerance and nonadherence are recognized limitations of CPAP therapy, the current body of evidence provides support for its positive effects on sleep quality and longer-term health outcomes. Furthermore, as discussed in Appendix 2 of our review, there are several evidence-based strategies that clinicians can use to support patients who are struggling with CPAP.

The use of wakefulness-promoting medications such as modafinil to treat persistent hypersomnolence despite adequate treatment of OSA is supported by several randomized trials. ${ }^{6}$ Before initiating stimulants or wakefulness promoting agents, it is important to review other reasons for an incomplete clinical response to therapy, as described in our review. The clinical evaluation of these patients may include ensuring treatment efficacy and ruling out other primary disorders of sleep, mood disorders, chronic pain, or medical conditions or medications that worsen sleep. A formal assessment by a sleep specialist may be of value in this situation.

\section{Cheryl R. Laratta MD}

Respirologist, Department of Medicine, University of Alberta, Edmonton, Alta.

\section{Najib T. Ayas MD MPH}

Respirologist, Department of Medicine, University of British Columbia,

Vancouver, BC

\section{Marcus Povitz MD MSc}

Respirologist, Department of Medicine, Western University, London, Ont.

\section{Sachin R. Pendharkar MD MSC}

Respirologist, Department of Medicine, University of Calgary, Calgary, Alta.

Cite as: CMAJ 2018 May 7;190:E573. doi: 10.1503/cmaj.69278

\section{References}

1. Laratta CR, Ayas NT, Povitz M, et al. Diagnosis and treatment of obstructive sleep apnea in adults. CMAJ 2017;189:E1481-8.

2. Pupko HA. Medical marijuana in treating obstructive sleep apnea [letter]. CMAJ 2018;190:E572.

3. Carley DW, Prasad B, Reid KJ, et al. Pharmacotherapy of apnea by cannabimimetic enhancement, the PACE clinical trial: effects of dronabinol in obstructive sleep apnea. Sleep 2018 Jan 1; 41(1). doi:10.1093/sleep/zsx184.

4. Rotenberg B, Pang K. Surgery for obstructive sleep apnea [letter]. CMAJ 2018;190:E444.

5. Interventions for the treatment of obstructive sleep apnea in adults: a health technology assessment [optimal use report]. Vol 6, No $1 \mathrm{~b}$. Ottawa: Canadian Agency for Drugs and Technologies in Health (CADTH); 2017.

6. Chapman JL, Vakulin A, Hedner J, et al. Modafinil/armodafinil in obstructive sleep apnoea: a systematic review and meta-analysis. Eur Respir J 2016;47:1420-8.

Competing interests: None declared. 